\title{
AUTONOMIA MUNICIPAL E INTERDEPENDÊNCIA FEDERATIVA: UMA ANÁLISE SOBRE AS MUDANÇAS OCORRIDAS NO ACESSO E NOS GASTOS EM EDUCAÇÃO NO BRASIL (2000-2014)*
}

Paulo Loyola ${ }^{1}$

\begin{abstract}
RESUMO: O principal objetivo deste artigo é explorar as mudanças que têm ocorrido no acesso à educação básica e nos gastos dos governos municipais brasileiros nos últimos anos (2000-2014), ressaltando a importância das relaçóes interfederativas para o provimento de políticas de educação. Os municípios têm papel central na análise, pois são os principais responsáveis pela promoçáo do acesso às creches, às pré-escolas e ao ensino fundamental. A interação com os outros níveis de governo é evidenciada em padróes de homogeneidade de acesso ao ensino e na influência das políticas do FUNDEF e do FUNDEB sobre a distribuição dos gastos com educação. Observa-se tendência de crescimento gradual nos gastos com a educação infantil e que, consequentemente, as creches tendem a ser as principais beneficiárias desse contexto de mudanças. Por fim, conclui-se que a tendência, nos anos recentes, do aumento na diversificação dos gastos entre os diferentes níveis de ensino é reflexo do crescimento na autonomia local sobre a política de educação e consequência de alteraçóes no policy decision making introduzidas por políticas do governo federal.
\end{abstract}

Palavras-chave: federalismo; autonomia local; acesso à educação; gastos em educação; municipalização do ensino.

\section{LOCAL GOVERNMENT AUTONOMY AND INTERDEPENDENCE AMONG JURISDICTIONS: ANALYSIS OF THE CHANGES OCCURRED IN ACCESS AND SPENDING ON EDUCATION IN BRAZIL (2000-2014)}

ABSTRACT: The main goal of this article is to explore the ongoing changes in access to basic education and local government's expenditures from 2000-2014 in Brazil, to stress the relations among jurisdictions for the provision of education policies. Municipalities play a central role in

\footnotetext{
*Este artigo resulta do Projeto FAPESP do CEPID/CEM, n. 2013/07616-7. Agradeço à minha orientadora, Profa. Marta Arretche, pelos comentários e as sugestóes em versão anterior deste trabalho. Também agradeço o cuidado e a atenção da Editora.

${ }^{1}$ Centro de Estudos da Metrópole (CEM) - São Paulo (SP), Brasil. E-mail: paulopcpl@gmail.com DOI: 10.1590/ES0101-73302017166662
} 
the analysis, since they are the main providers of daycares, preschools and elementary schools in Brazil. State governments affect local government decisions on education policy given that some of them display homogeneity of access. The FUNDEF and FUNDEB policies also play an important role on both the access and the distribution of spending. Spending on early childhood provision is increasing gradually and daycare users tend to be the major beneficiaries in this context of change. Finally, the conclusion is that the trend, in recent years, of diversification of spending between different levels of education is a reflection of the increase of local autonomy on the education policy and it is a consequence of changes in the policy decision making made by the federal government.

Keywords: federalism; local autonomy; access to education; spending in education; municipalization of education.

\section{L'AUTONOMIE MUNICIPALE ET L'INTERDÉPENDANCE FÉDÉRATIVE: UNE ANALYSE DES CHANGEMENTS D'ACCÈS ET DE DÉPENSES EN MATIÈRE D'ÉDUCATION AU BRÉSIL (2000-2014)}

RESUME: L'objectif principal de cet article est d'étudier les changements intervenus de 2000 à 2014 en ce qui concerne l'accès à l'éducation de base et les dépenses des administrations municipales brésiliennes, en soulignant l'importance des relations entre les juridictions pour la mise en œuvre des politiques éducatives. Les communes jouent un rôle central dans l'analyse, puisque elles sont les principales responsables de la promotion de l'accès aux crèches, aux écoles maternelles et élémentaires. L'interaction avec les autres ordres de gouvernement est illustrée par les modèles d'homogénéité de l'accès à l'éducation et par l'influence des politiques du FUNDEF et du FUNDEB sur la répartition des dépenses d'éducation. On constate une tendance à l'augmentation progressive des dépenses consacrées à l'éducation de l'école maternelle et, par conséquent, les crèches ont une tendance à être les principaux bénéficiaires de ce contexte de changements. Il s'ensuit que la tendance ces années à une diversification accrue des dépenses entre les différents niveaux de scolarité reflète l'augmentation de l'autonomie locale par rapport à la politique de l'éducation et la conséquence des changements apportés par le gouvernement fédéral à la prise de décisions politiques.

Mots-clés: fédéralisme; autonomie locale; accès à l'éducation; dépenses en éducation; municipalisation de l'éducation.

\section{Introdução}

Não se deve alimentar a ilusão de que as normas legais 'resolvem', por si mesmas, os dilemas sociais. Mas os pioneiros estavam certos: elas criam deveres minimos, estimulam a distribuição crescente das oportunidades educacionais e abrem aos trabalhadores canais de acesso a todos os niveis de ensino.

Florestan Fernandes 


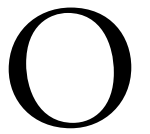

s municípios brasileiros ocupam papel central no desenvolvimento das políticas de educação no País. Eles são os principais entes federados responsáveis pela realização de matrículas na educação infantil e no ensino fundamental. Ainda assim, são escassos os estudos que mostram discricionariamente como eles têm desempenhado suas atribuiçóes no período recente, tendo em vista as relaçôes entre os governos nos diferentes níveis da federação e os estímulos e constrangimentos impostos por tais ligações.

Nesse sentido, destaca-se a influência do governo federal sobre a agenda de educação dos governos subnacionais mediante a execução de suas políticas e aprovação de legislação incidente sobre áreas de atuação que competem aos demais entes federados. No caso da educação, a Lei de Diretrizes e Bases da Educação Nacional (LDB), o Fundo de Manutençáo e Desenvolvimento do Ensino Fundamental e de Valorização do Magistério (FUNDEF) e o Fundo de Manutenção e Desenvolvimento da Educação Básica e de Valorização dos Profissionais da Educação (FUNDEB) são bons exemplos de como o governo federal influencia o policy making e o policy decision making dos governos subnacionais. Tanto a LDB quanto os dois fundos influenciaram as políticas implementadas pelos governos subnacionais ao delimitar quais gastos deveriam ser considerados como direcionados à manutençáo e ao desenvolvimento do ensino, e ao estabelecerem estímulos para que os governos subnacionais expandissem o acesso ao ensino fundamental e à educação básica, respectivamente.

Os governos estaduais também exercem importante influência sobre a política de educação dos municípios (GOMES, 2009). Isso ocorre, principalmente, em relação ao ensino fundamental, pois os governos estaduais ainda têm participaçáo relevante na oferta de acesso a ele, apesar de sua participação continuar a declinar com o tempo, como é mostrado neste artigo. No ensino fundamental, as decisóes do governo estadual podem fazer com que as redes estadual e municipal de ensino disputem alunos e recursos ou fazer com que se coordenem de modo a transmitir as responsabilidades pela garantia do acesso ao ensino a uma das duas redes.

As redes municipais de ensino, apesar de terem de lidar com tais constrangimentos e com restrições orçamentárias, apresentam importantes diferenças entre si. Os constrangimentos existentes náo são suficientes para eliminar a importância que o governo local tem sobre a política de educação municipal. Assim, o objetivo deste trabalho é fazer um diagnóstico do acesso à educação no período de 2000 a 2014 e das escolhas que os prefeitos têm feito sobre alocação de recursos e prioridades de gastos em educação no Brasil.

As relaçóes federativas têm papel central nesse trabalho, pois elas são capazes de gerar estímulos e obstáculos com os quais os demais governos terão de lidar ao tomar suas decisōes sobre políticas e ao tratar das diferentes questôes que envolvem suas respectivas políticas de educação. 
A participação da rede municipal de ensino é destacada, pois ela é a maior rede pública do País ofertante de vagas em educação infantil e em ensino fundamental - o que implica que as redes de ensino municipais são as que atendem ao maior número de alunos no País inteiro. $\mathrm{O}$ município também é o ente federado mais próximo dos cidadãos e, por isso, é nele que melhor se observam as consequências das escolhas feitas pelos governos dos diferentes entes federados. Desta forma, observar e entender a política de educação nos municípios brasileiros é de grande importância para se entender a política de educação no Brasil.

A ampliação do acesso não implica melhora na qualidade do ensino. Entretanto, a universalização do acesso ao ensino é etapa importante a ser alcançada para garantir melhores e iguais oportunidades de educação a todos. Neste artigo, acesso e qualidade do ensino não se confundem. Essa análise explora questôes relativas ao acesso ao ensino e às prioridades dos governos municipais em relaçáo aos seus gastos em educação. Destaca-se que os avanços ocorridos nestas áreas não devem ser confundidos com diagnósticos sobre a qualidade do ensino nas salas de aula.

Este artigo divide-se em cinco tópicos, sendo o primeiro esta introdução. No segundo tópico (A educação municipal e seu contexto institucional), apresenta-se a bibliografia com a qual este estudo dialoga e as principais políticas federais que estruturam as relações entre os diferentes entes federados no campo da educação; descreve-se o cenário sobre o qual se discorrerá com maior detalhe ao longo do artigo. No terceiro tópico (Trajetória das matrículas), discorre-se sobre o comportamento das matrículas nos diferentes níveis de ensino e o papel da rede municipal em comparação com as demais redes de ensino; destacam-se as mudanças e tendências nas políticas adotadas pelas diferentes redes de ensino. No quarto tópico (Gastos em educação), os gastos em educação nos municípios e a influência que a legislação federal tem sobre eles são analisados. Por fim, a conclusão, quinto tópico, retoma os principais achados deste trabalho e disserta sobre qual o espaço ocupado pelos governos municipais na promoção do acesso à educação no País.

\section{A educação municipal e seu contexto institucional}

A Constituição de 1988, ao reconhecer os municípios como entes da federação brasileira, fez com que o número de sistemas de ensino existentes no País, que antes equivalia a um sistema para cada estado, crescesse a ponto de termos um sistema de ensino para cada município, mais os antigos sistemas estaduais (DUARTE, 2005; RODRIGUEZ, 2001; SOUZA; FARIA, 2004). À fragmentação oriunda desta medida somou-se outra norma centralizadora e limitadora da autonomia dos entes subnacionais: a obrigação constitucional de que os municípios e estados gastem em ensino $25 \%$ de suas receitas arrecadadas de impostos. Dessa forma, enquanto houve multiplicação das instâncias responsáveis administrativamente por gerir a política de educação, existiu manutenção da obrigação de direcionar parte das receitas à educação ${ }^{1}$. 
As restriçóes apresentadas aos municípios pelo arcabouço legal que estrutura as relações federativas no campo da política educacional não devem ser interpretadas como determinantes de certos resultados por si mesmos. Apesar de haver considerável número de restriçôes e de estímulos para que os municípios adotem certas políticas e se desviem de outras, ainda há aceitável espaço de manobra para que os prefeitos possam adotar estratégias diferentes para enfrentar problemas observados localmente. A construção de escolas e creches ou a realização de convênios com entidades privadas sáo escolhas distintas que podem ser feitas por um prefeito para solucionar o mesmo problema: atender à demanda por vagas em seu município.

Os prefeitos têm importante poder discricionário sobre a política local de educação, e as políticas implementadas pelo governo federal no pós 1988 não acabaram com esta discricionariedade, apenas tornaram-na mais complexa.

Os fundos (FUNDEF e FUNDEB) deram novos estímulos aos prefeitos e governadores e, por isso, também geraram novos resultados. No entanto, as articulaçóes entre prefeitos e governadores sempre foram importantes para o desenvolvimento da política local de educação. Na Constituição de 1988 foi estabelecido que estados e municípios podem legislar sobre muitos temas em comum, entre eles a educação. Isso trouxe como consequência a existência de competiçóes entre ambos os entes pela oferta de serviços semelhantes, gerando baixa eficiência e desperdício de recursos públicos. A possibilidade de concorrência, conflito ou cooperação entre os entes federados mostra que é necessário examinar a política local de educação em um contexto mais amplo no qual as escolhas dos prefeitos de implementarem certas políticas podem ser influenciadas também por escolhas feitas por governadores (GOMES, 2009) ou por prefeitos de municípios vizinhos.

Como consequência da discricionariedade da qual dispóem prefeitos e governadores no exercício de seus mandatos, nem todas as políticas implementadas pelo governo federal implicam um efeito imediato na política dos governos subnacionais (GOMES, 2009). Os resultados de certas políticas do governo federal dependem de como os governos subnacionais decidem interagir com elas.

Nesse cenário de crescente complexidade da participação do governo federal no policy making dos governos subnacionais (ARRETCHE, 2009; SÁTYRO, 2008), a política local de educação reflete camadas de escolhas que se sobrepóem e que são resultados das interações de atores ocupantes de cargos em diferentes níveis do governo. Dessa forma, por exemplo, entender como a LDB e o FUNDEF influenciaram o policy making dos governos subnacionais é essencial para entender a implementação das políticas e os resultados observados e ir além das consequências esperadas, expressas no próprio texto das leis que promulgaram tais medidas.

Sabe-se que a LDB enrijeceu a aplicação de recursos em educação, minimizando as possibilidades de que fossem utilizados com outras finalidades (SEMEGHINI, 2001). Isso foi feito para impedir que governadores e prefeitos desviassem recursos da educação e os destinassem a outras áreas. Entretanto, a 
pouca disponibilidade de microdados para o período que engloba a implementação da LDB torna difícil de investigar como os governos subnacionais passaram a interagir com essa medida. $\mathrm{O}$ mesmo não ocorre para o FUNDEB, que é uma política do governo federal que visa à ampliação do acesso ao ensino, que foi implementada a partir de 2007 e é uma continuaçáo do FUNDEF.

O FUNDEF constituiu-se em um sistema de fundos estaduais que recolhia parte da receita arrecadada dos municípios e Estados e a redistribuía de acordo com o número de matrículas no ensino fundamental que os governos subnacionais tivessem apresentado no ano anterior em suas próprias redes de ensino. A emenda constitucional do FUNDEF foi parte de uma política do governo federal para estimular a expansão da oferta de matrículas no ensino fundamental visando sua universalização. Apesar de muito criticado, é possível dizer que o FUNDEF, combinado com programas como o Bolsa-Escola, o Bolsa-Família e o Programa de Erradicação do Trabalho Infantil (PETI), alcançou seu objetivo (CAMPOS; CRUZ, 2009).

Como consequência do FUNDEF (COSTA; DUARTE, 2008; PINTO, 2002) e da articulação entre governadores e prefeitos (COSTA; DUARTE, 2008; GOMES, 2009), a rede municipal passou a ser a principal gestora do ensino fundamental na federação. No entanto, o FUNDEF, implementado a partir de 1998, possuía um prazo de duração limitado até 2006 e, a partir de 2007, o fundo foi substituído pelo FUNDEB, que manteve boa parte da lógica de funcionamento do fundo anterior, mas passou a realizar os repasses de receita de acordo com as matrículas realizadas em toda a educação básica, em conformidade com diferentes pesos atribuídos para matrículas em diversos níveis e modalidades de ensino.

Ambos os fundos inserem-se em um contexto de políticas de ampliação do acesso ao ensino desenvolvidas pelo governo federal. São políticas que visam à eliminação da situação em que desigualdades socioeconômicas contribuem para a determinação das disparidades educacionais do País. Como é mostrado neste artigo, nota-se progresso no acesso ao ensino ocorrendo em todo o País, mas esse progresso também é marcado por peculiaridades características dos diferentes níveis de ensino e dos diferentes estados e regióes nacionais.

\section{Trajetória das matrículas}

Este tópico apresenta dados sobre o número total de matrículas por nível (creche, pré-escola e ensino fundamental) e por rede de ensino (municipal, estadual, federal e particular) no Distrito Federal e em todos os municípios e estados brasileiros.

O período examinado diz respeito aos anos de 2000 a 2014. Para o período anterior à implementação do FUNDEF, não há microdados passíveis de desagregação por municípios em intervalos anuais sem perda significativa de qua- 
lidade. Por isso, a análise começa em 2000 e segue até o período mais recente que apresenta dados disponíveis para consulta.

\section{Creches}

Nos últimos anos, o Brasil tem passado por transformaçóes demográficas capazes de influenciar no desenho e nos resultados das políticas públicas de acesso ao ensino. O envelhecimento populacional (RIGOTTI, 2012) e a diminuição na taxa de fertilidade da população feminina (BERQUÓ; CAVENAGHI, 2006) fizeram com que a demanda por vagas em estabelecimentos de ensino tenha se reduzido ao longo dos anos, de modo que seria possível obter aumento na taxa de acesso ao ensino simplesmente mantendo-se a oferta de número constante de vagas nesses estabelecimentos. Se, por um lado, essas transformaçôes podem carregar implicaçốes negativas para o mercado de trabalho e para o setor previdenciário, elas contribuem para que o acesso ao ensino seja universalizado em toda a educação básica.

As creches no Brasil sempre apresentaram baixo atendimento às demandas por vagas. Apesar de o acesso a este nível de ensino ter crescido de maneira significativa ao longo dos últimos anos, as creches ainda correspondem ao nível de ensino que mais precisa crescer para conseguir atender plenamente toda a demanda existente.

A expansão da oferta de vagas em creches, a partir de 2000, teve duas fases distintas devido à implementação do FUNDEB. Anteriormente à criação do fundo, já havia um movimento de expansão das creches; entretanto, a velocidade com que ele ocorria era bem menor do que no período posterior a sua implantação. Segundo os dados do Censo Escolar, no período de 2000 a 2006, houve um crescimento no número de vagas em creches de $55,74 \%$, enquanto no período compreendido entre 2007 e 2013 o número de vagas em creches foi ampliado em 72,84\%. Assim, apesar de o FUNDEF desestimular o investimento em creches devido à clara prioridade dada ao ensino fundamental (COSTA; DUARTE, 2008; OLIVEIRA, 2012), em seu período de vigência houve razoável crescimento do número de matrículas nesses estabelecimentos. Consequentemente, o FUNDEB não é o único motivo pelo qual a expansão nas creches ocorreu, mas é um dos principais responsáveis por sua aceleração no período subsequente.

Houve crescimento das matrículas em creches (Gráfico 1) e o atendimento à demanda ${ }^{2}$ por vagas nessas instituiçóes cresceu significativamente a partir de 2007 (Gráfico 2). Nesse período, houve também queda significativa da população de zero a três anos no País (Gráfico 3), o que fez com que a expansão do número de matrículas em creches fosse combinada com a queda na demanda, levando a que, ao final do período, um percentual próximo a $23 \%$ da procura no País por vagas em creches tivesse atendimento. 
Entretanto, o atendimento à demanda por matrículas em creches encontrase ainda em nível muito baixo. Há padróes regionais e fatores locais que influenciam no acesso às creches no País. $\mathrm{O}$ acesso às creches, em 2012, é um bom exemplo disso. Nesse ano, a região Norte apresentou os piores índices de acesso às creches e o estado do Rio Grande do Sul significativa desigualdade de acesso às creches entre seus municípios. A combinação entre desigualdade e baixa capacidade de atendimento são intrínsecas à situação de acesso às creches no País. Isto certamente é consequência do baixo nível de prioridade que, historicamente, foi dada às creches em relação aos outros níveis de ensino. A desigualdade de acesso é grande mesmo nos municípios dentro

\section{Gráfico 1}

Matrículas em creches no Brasil.

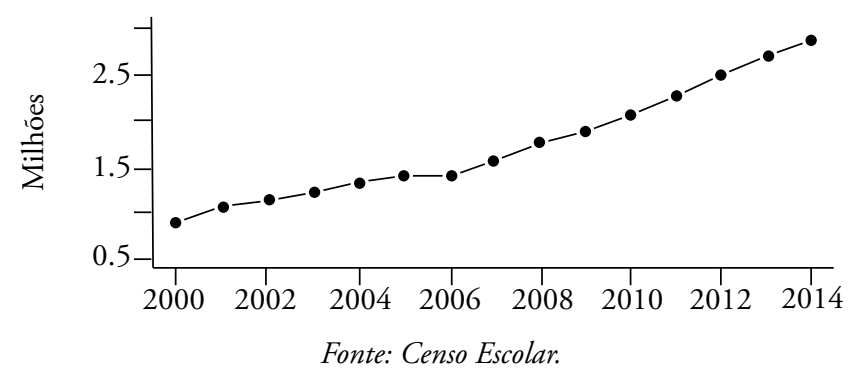

Gráfico 2

Demanda por creches atendidas.

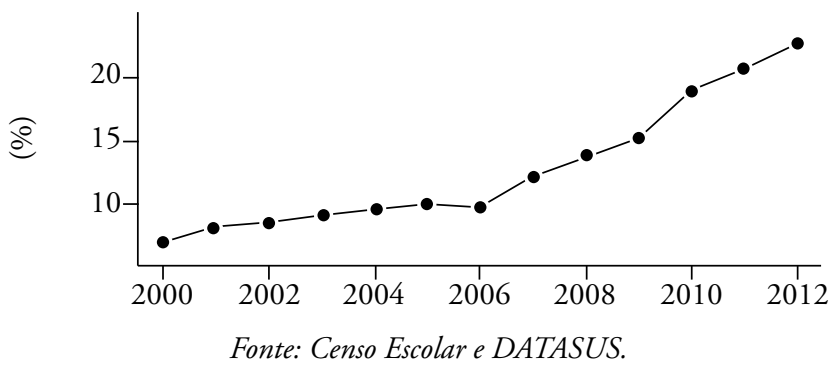

Gráfico 3

População de zero a três anos.

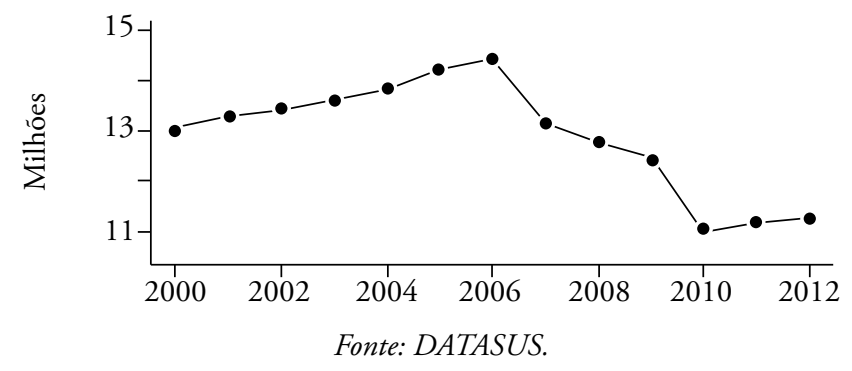


dos estados que apresentam os melhores índices (Figura 1 e Gráfico 4). São Paulo é o estado com o maior percentual médio de crianças de zero a três anos matriculadas em creches mas, ainda assim, também é um dos estados com maior variação no percentual de crianças matriculadas em creches por município. Logo, apesar de ser o estado que mais atende à demanda por vagas em creches, também é um dos mais desiguais em relação a como esse atendimento distribui-se entre seus municípios.

\section{Figura 1}

Percentual de crianças matriculadas em creches nos municípios brasileiros em 2012.

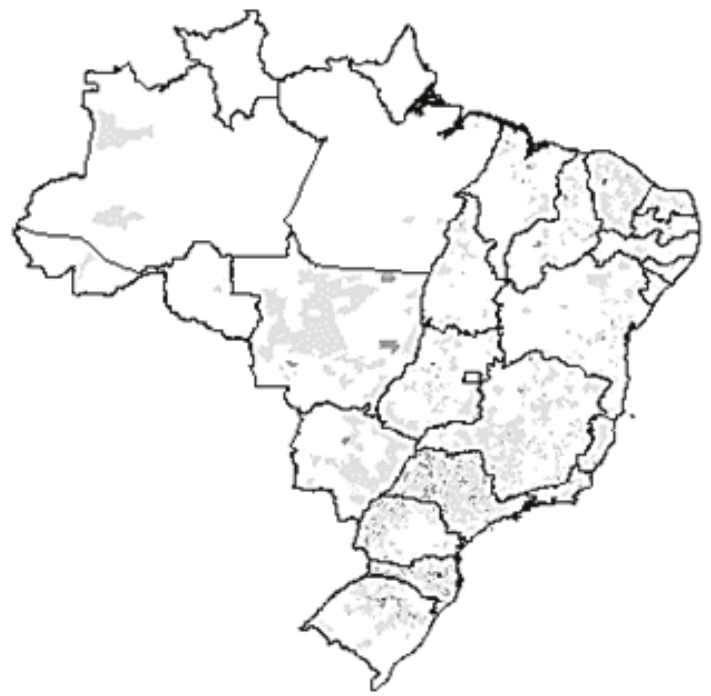

Crianças matriculadas

$\begin{array}{ll}\square 0 \text { a } 25 \% & \square 75 \text { a } 95 \% \\ \square 25 \text { a } 50 \% & \square+\text { de } 95 \% \\ \square & 50 \text { a } 75 \%\end{array}$

Fonte: Censo Escolar e DATASUS.

\section{Gráfico 4}

Percentual de crianças matriculadas em creches nos municípios brasileiros em 2012 - Desvio padrão e média por estado e Distrito Federal.

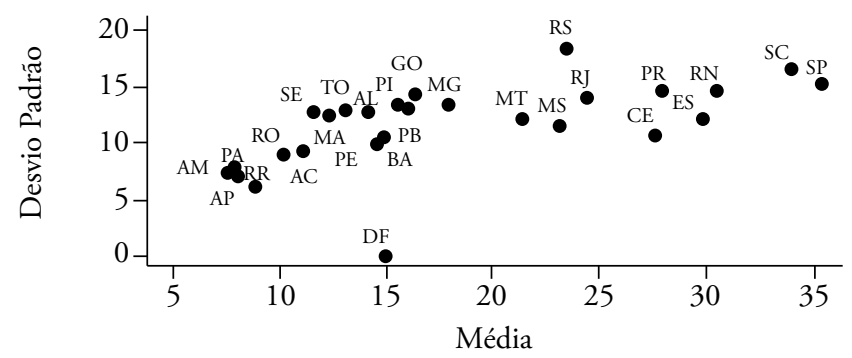

Fonte: Censo Escolar e DATASUS. 
Devido aos governos municipais serem os principais ofertantes de matrículas em creches, parte significativa dessa desigualdade também é decorrente da diversidade de capacidade financeira dos municípios brasileiros em arcar com os custos de construção e manutenção de creches. Como a maior parte dos recursos reservados à educação já estavam alocados em outros níveis de ensino quando o acesso às creches passou a receber maior atenção dos governos, o FUNDEB constituiu-se em mecanismo essencial para a expansão do ingresso nessas instituições no País.

A partir de 2007, as redes municipais e privadas de ensino aumentaram a velocidade de expansão de suas creches devido aos estímulos dados pelo FUNDEB. O fundo incluiu as matrículas em creches no cálculo dos recursos que deveriam ser repassados aos governos subnacionais, de modo que os governos passaram a receber mais recursos de acordo com o número de matrículas em creches registradas em suas redes de ensino no ano anterior. O FUNDEB também permitiu que os governos municipais recebessem repasses por matrículas realizadas em creches de redes conveniadas, de maneira que também favoreceu o crescimento das redes privadas de creches (Gráficos 5 e 6 ).

Os governos locais sempre foram os principais responsáveis pelo oferecimento de vagas em creches e sua tendência de crescimento, a partir de 2007, mostra

\section{Gráfico 5}

Matrículas em creches por dependência administrativa.

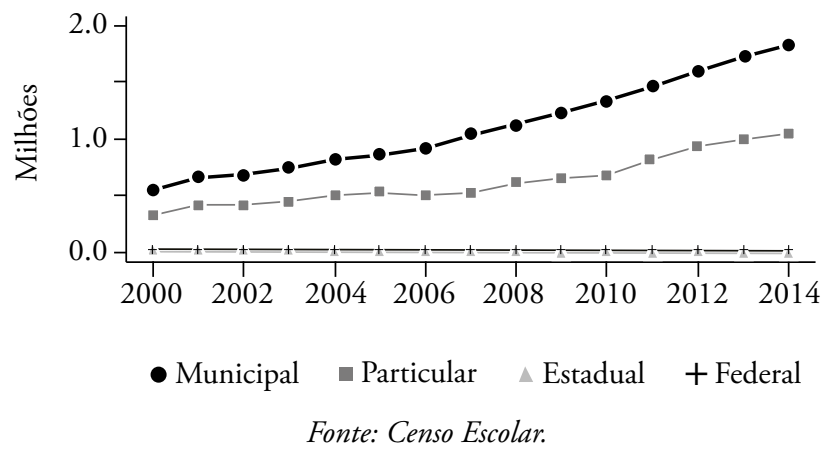

Gráfico 6

Matrículas em creches (\%) por dependência administrativa.

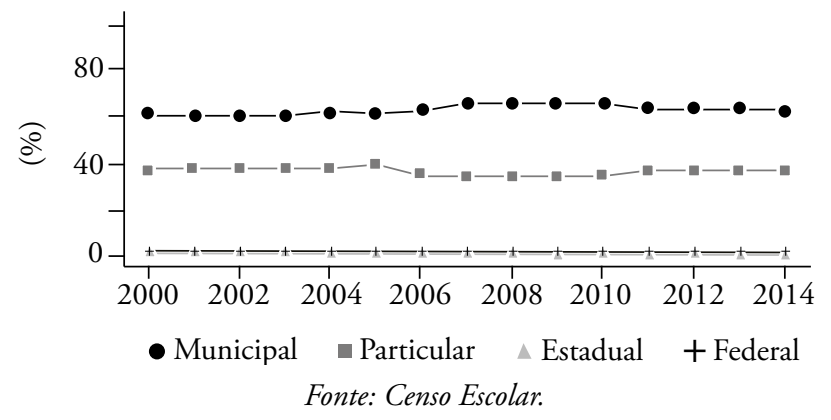


que este perfil tenderá a se manter. As duas maiores questôes em relação à oferta de matrículas em creches dizem respeito às desigualdades de acesso influenciadas por fatores regionais ou locais e às escolhas que os governos locais fazem entre estabelecer e expandir uma rede própria ou recorrer a convênios com entidades privadas.

$\mathrm{O}$ acesso às creches nos anos recentes mostra que ainda há considerável número de obstáculos que devem ser superados até que se alcance a universalização de ingresso neste nível de ensino. Os governos municipais são atores centrais neste processo e medidas de expansão do acesso devem sempre ser dirigidas a ampliar a capacidade destes governos de responder às demandas de seus cidadáos mediante o fornecimento de estímulos que conduzam à superação de suas limitaçóes orçamentárias.

\section{Pré-escolas}

Apesar de as pré-escolas integrarem a educação infantil juntamente com as creches, a evolução das matrículas nesse nível de ensino apresenta comportamento diferente do movimento observado das matrículas em creches. Contrariamente ao esperado, o número de matrículas na pré-escola cresceu durante o período de vigência do FUNDEF e caiu durante o período de vigência do FUNDEB (Gráfico 7).

Essa mudança sugere que, após terem alcançado níveis elevados de acesso ao ensino fundamental, houve esforço de alguns municípios para ampliar o ingresso na educação infantil. Entretanto, esse movimento perdeu força após a aprovação do ensino fundamental com duraçáo de nove anos (Lei 11.274/2006), que ocorreu com a incorporação de crianças de seis anos no ensino fundamental e transformou o ensino pré-escolar em um ciclo de apenas dois anos, destinado às crianças de quatro e cinco anos de idade ${ }^{3}$. Essa mudança retirou estímulos para que os municípios dedicassem-se à expansão da pré-escola e mesmo os incentivos dados pelo FUNDEB foram incapazes de compensar a perda criada pela Lei 11.274/2006.

A implementação do ensino fundamental com duração de nove anos causou a redução da população em idade ideal para se matricular em pré-escolas

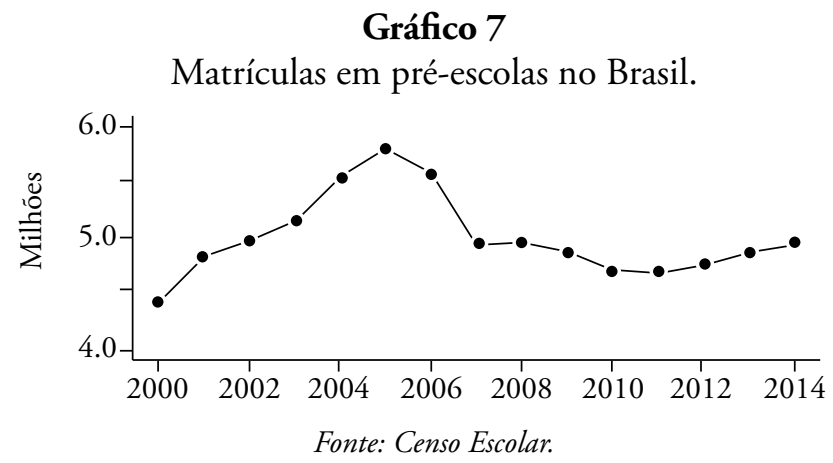


(Gráfico 8) e, consequentemente, aumentou o percentual de crianças nesse grupo atendido (Gráfico 9). $\mathrm{O}$ atendimento à demanda por vagas em pré-escolas, que era em torno de 44\% da demanda, em 2000, passou para mais de 80\%, em 2012.

$\mathrm{O}$ acesso às pré-escolas tem se homogeneizado em direção à universalização. Estados como São Paulo, Santa Catarina e Ceará já garantiram, na maioria de seus municípios, um mínimo de $80 \%$ de acesso às pré-escolas, em 2012. Apesar de, nesse ano, as regióes Sul, Centro-Oeste e Norte apresentarem maior heterogeneidade do que as demais no acesso às pré-escolas, o País como um todo apresenta um quadro bem mais amplo de acesso do que o observado em 2000 (Figura 2 e Gráfico 10).

As desigualdades de acesso no interior dos estados reduziram-se assim como as existentes entre os estados. As regióes Norte e Centro-Oeste continuaram sendo as regióes com os piores índices de acesso, apesar de terem melhorado consideravelmente em relaçáo ao ano 2000, tanto em termos de acesso quanto em termos de redução da desigualdade de acesso entre seus municípios.

\section{Gráfico 8}

População de quatro a cinco anos de idade e de quatro a seis anos de idade.

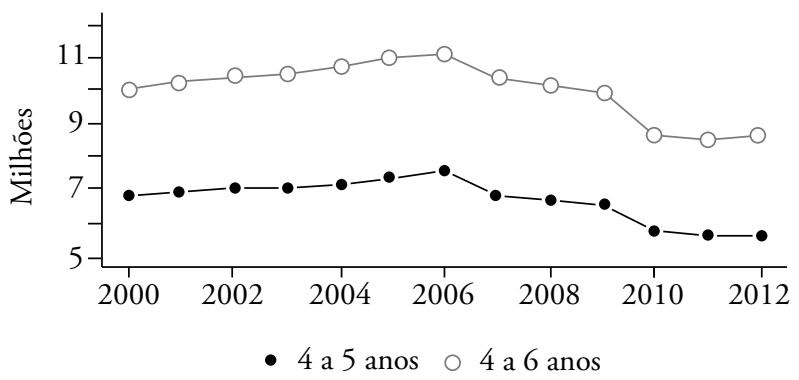

Fonte: DATASUS.

\section{Gráfico 9}

Demanda por pré-escolas atendidas.

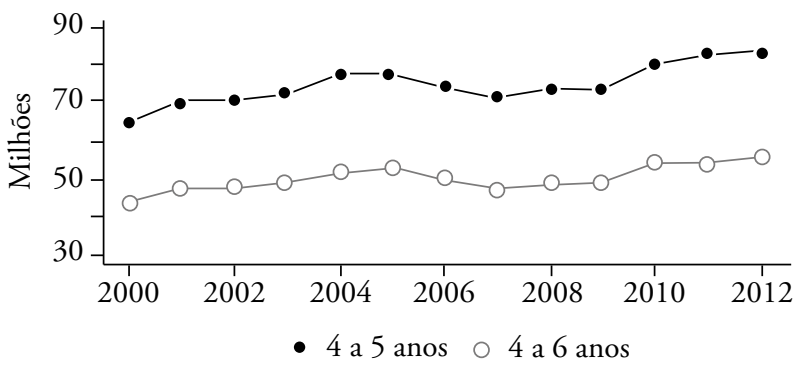

Fonte: Censo Escolar e DATASUS. 
O estado de Sergipe destaca-se por apresentar municípios com média de acesso acima de $100 \%$, o que indica que seus municípios tenderam a matricular crianças acima da idade ideal em pré-escolas. $\mathrm{O}$ elevado desvio padrão do acesso às pré-escolas em Sergipe também sugere que alguns municípios daquele estado assumiram papel central na oferta de matrículas e ofereceram número de vagas consideravelmente superior à sua população em idade ideal para frequentar aquele nível de

\section{Figura 2}

Percentual de crianças matriculadas em pré-escolas nos municípios brasileiros em 2000 e em 2012.

2000

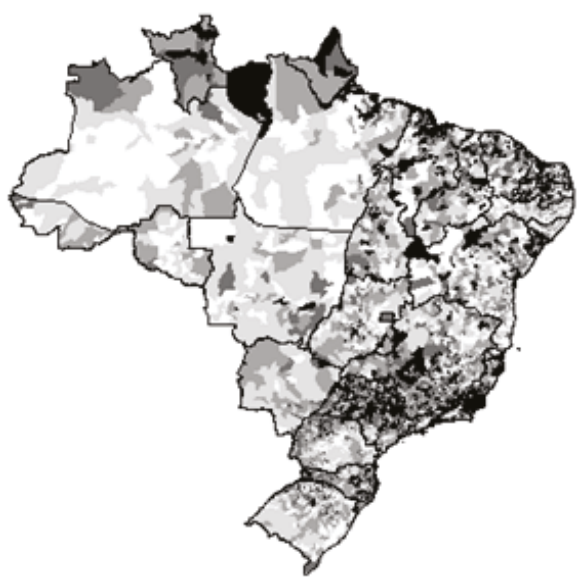

2012

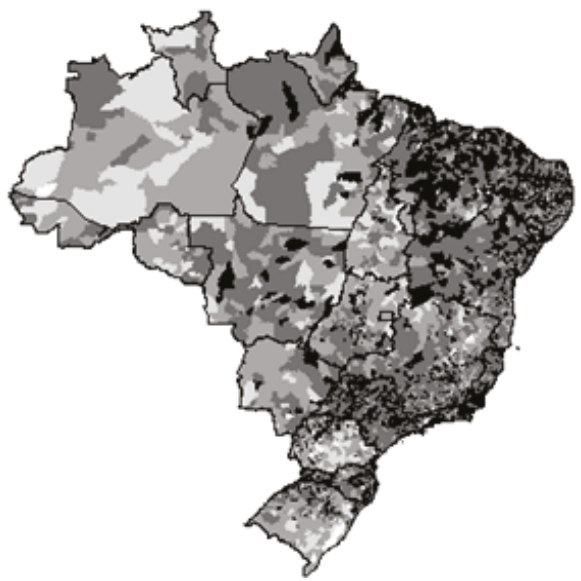

Crianças matriculadas

$$
\begin{array}{ll}
\square \text { 0 a } 25 \% & \square 75 \text { a } 95 \% \\
\square 25 \text { a } 50 \% & \square+\text { de } 95 \% \\
\square 50 \text { a } 75 \% &
\end{array}
$$

Fonte: Censo Escolar e DATASUS.

\section{Gráfico 10}

Percentual de crianças matriculadas em pré-escolas nos municípios brasileiros em 2000 e em 2012 - Desvio padrão e média por estado e Distrito Federal.

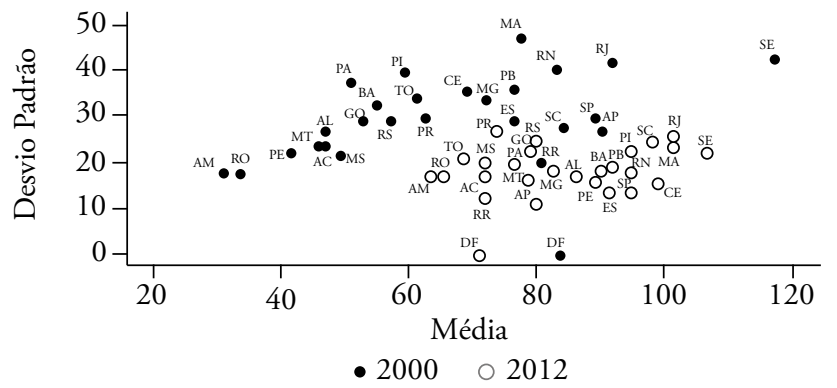

Fonte: Censo Escolar e DATASUS. 
ensino. Em 2012, já havia ocorrido maior homogeneização do acesso à pré-escola no estado, seus municípios tornaram-se mais iguais e diminuiu a influência de alguns poucos municípios sobre o total de matrículas oferecidas em Sergipe.

Os Gráficos 11 e 12 mostram o predomínio das redes municipais e privadas na oferta de matrículas em pré-escolas. O declínio no número de matrículas na rede municipal sem reflexo positivo nas matrículas das outras redes de ensino deriva, em parte, da variação demográfica ocorrida no período. Já o declínio no número de matrículas da rede estadual não influenciou de maneira significativa a oferta de matrículas nas outras redes de ensino. Esse declínio sugere uma escolha dos governos estaduais em reduzir sua participação na educação infantil.

Como consequência de diretrizes adotadas pelo governo federal para a política de educaçáo no período recente, o papel da pré-escola na educaçáo infantil foi reduzido e isso influenciou as escolhas que os gestores locais fizeram sobre a expansão do acesso a esse nível de ensino. Tendo maior demanda não atendida de acesso às creches, a tendência foi de que os gestores escolhessem priorizar o acesso a estas em detrimento do acesso às pré-escolas. Este trade off fica em maior evidência no próximo tópico (Gastos em Educação), em que é mostrado que, a partir de 2010, houve aumento no percentual de receitas municipais destinadas à educaçáo infantil, e observa-se que houve aumento do acesso às creches mas, também, estagnação no número de matrículas em pré-escolas.

\section{Gráfico 11}

Matrículas em pré-escolas por dependência administrativa.

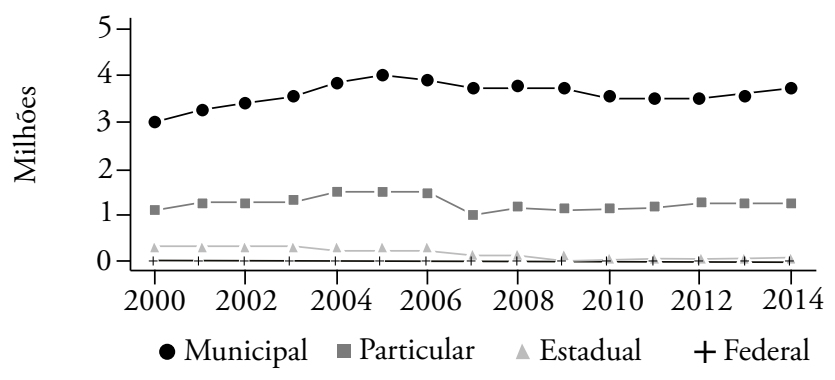

Fonte: Censo Escolar.

Gráfico 12

Matrículas em pré-escolas (\%) por dependência administrativa.

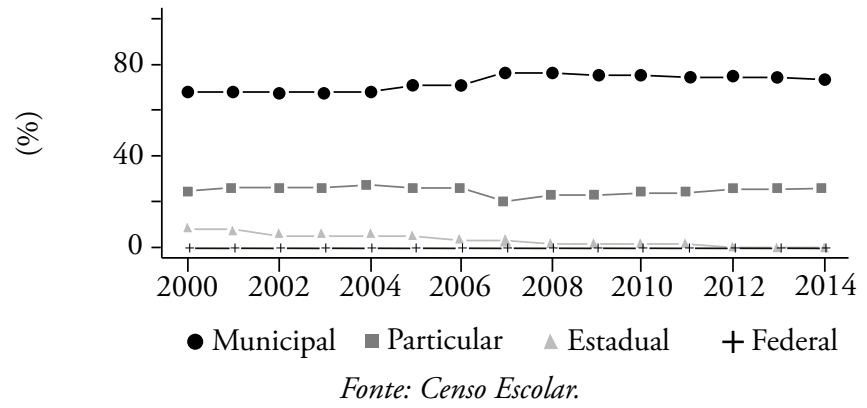




\section{Ensino fundamental}

O ensino fundamental difere dos demais níveis de ensino, pois o acesso a ele já está universalizado (AGUIAR, 2010; CAMPOS; CRUZ, 2009). Como consequência disso, das mudanças demográficas ocorridas no País e da diminuiçáo do desvio idade-série, tem ocorrido redução em ritmo quase constante do número absoluto de matrículas nesse nível de ensino (Gráfico 13).

O total da razão entre o número de matrículas no ensino fundamental e a população em idade ideal para frequentar esse nível de ensino com valor superior a $100 \%$ reflete o desvio idade-série presente no ensino fundamental somado à universalização do acesso (Gráficos 14 e 15).

Como o acesso ao ensino fundamental já estava universalizado em 2000, a diminuição no número de vagas ocorrida no período não implica redução do acesso ao ensino, mas declínio da distorçâo idade-série.

Devido à universalização do acesso ao ensino fundamental já ter ocorrido, a evolução da oferta de matrículas para este nível de ensino, ao longo dos anos,

\section{Gráfico 13}

Matrículas no ensino fundamental no Brasil.

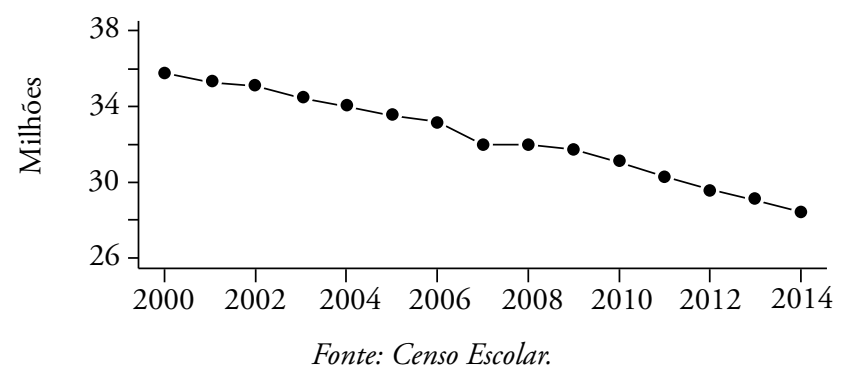

\section{Gráfico 14}

População de seis a catorze anos de idade e de sete a catorze anos de idade.

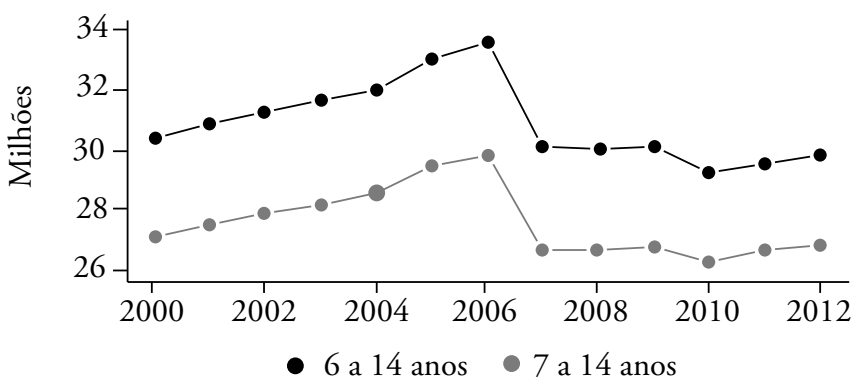

Fonte: DATASUS. 
mostra com maior detalhe o processo de municipalização do ensino fundamental. Os governos estaduais têm participação cada vez menor na oferta de matrículas e os municípios, consequentemente, ocupam espaço maior (Gráficos 16 e 17).

Cada uma das redes de ensino teve um comportamento específico durante o período. A rede estadual manteve-se em declínio e, ao final de um período

\section{Gráfico 15}

Demanda por ensino fundamental atendida.

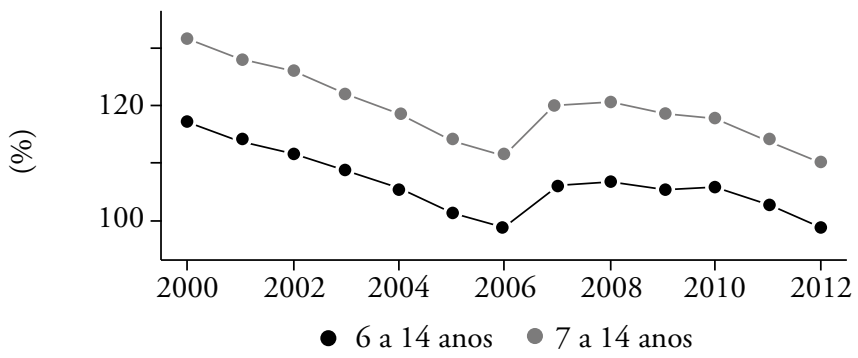

Fonte: Censo Escolar e DATASUS.

Gráfico 16

Matrículas no ensino fundamental por dependência administrativa.

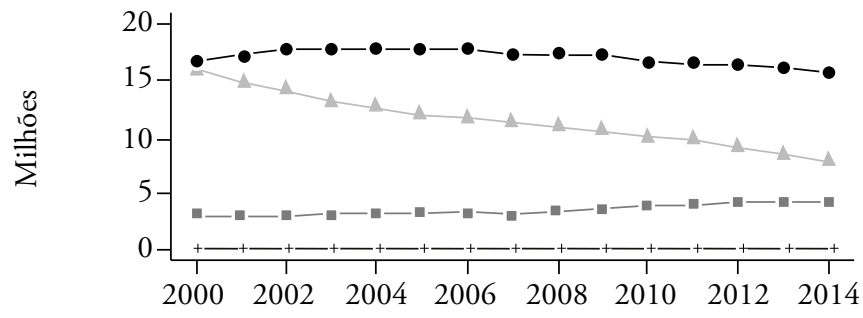

- Municipal $\backsim$ Particular $\triangle$ Estadual +Federal

Fonte: Censo Escolar.

Gráfico 17

Matrículas no ensino fundamental (\%) por dependência administrativa.

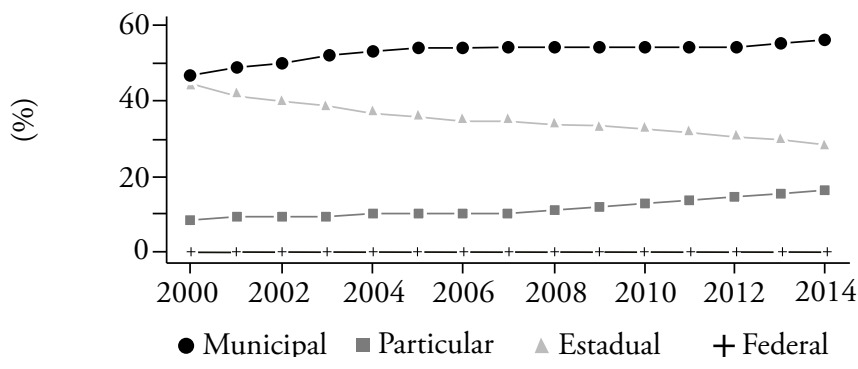

Fonte: Censo Escolar. 
de 15 anos, registrou número de matrículas próximo da metade daquele que tinha em 2000. Esse declínio de oferta é um indicador da interdependência existente entre as redes estaduais, municipais e particulares de ensino. A rede municipal apresentou leve aumento até 2005, mas passou a reduzir o número de matrículas de 2007 em diante. Já a rede particular teve pouca variaçáo até 2007, mas, a partir de 2008, começou a crescer em ritmo mais acelerado. Destaca-se que, após 2008, a rede particular de ensino foi a única que apresentou aumento em seu número absoluto de matrículas.

A coincidência entre a expansão das redes privadas com a implementação do FUNDEB mostra que os estímulos dados pelo governo federal são importantes indutores para a produção de políticas. A possibilidade de municípios receberem repasses do FUNDEB, referentes a matrículas realizadas em redes com as quais mantêm convênios, serviu de estímulo para o aumento nesses tipos de parcerias ao mesmo tempo em que diminuiu os incentivos para que os municípios ampliassem suas próprias redes. Entretanto, a participação do governo estadual na oferta de ensino fundamental também é importante, apesar de não ter o mesmo peso em todos os estados. Os mapas a seguir apresentam a participação das redes estaduais, municipais e privadas na oferta de vagas de ensino fundamental nos municípios brasileiros.

Os mapas da Figura 3 mostram os diferentes papéis ocupados pelas redes estaduais e municipais de ensino fundamental no Brasil e suas variaçóes ao longo

\section{Figura 3}

Rede dominante na oferta de ensino fundamental nos municípios brasileiros em 2000 e em 2012.

2000

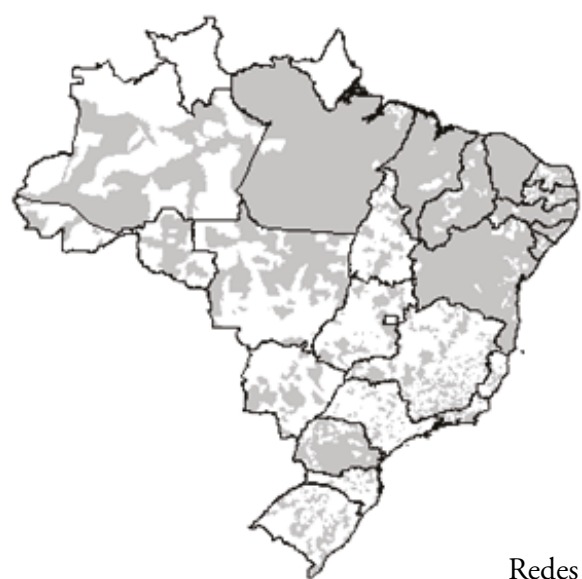

Redes
2012

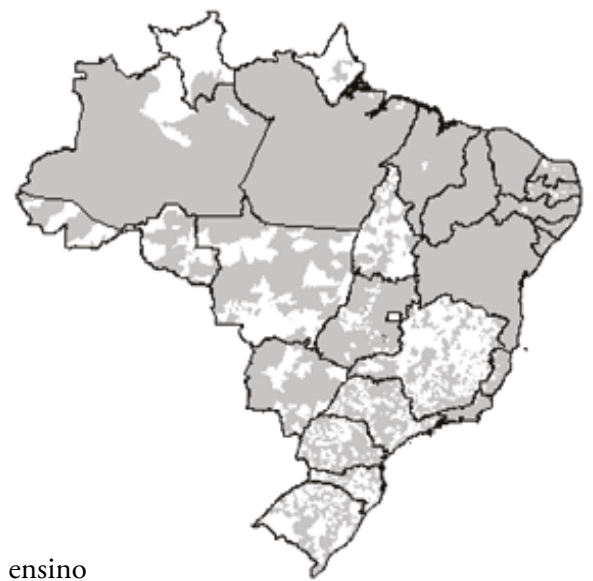

$\square$ Rede municipal

Nota: Os municipios onde predomina a rede particular de ensino são apenas $14 \mathrm{em} 2012$ e $1 \mathrm{em} 2000$. Fonte: Censo Escolar e DATASUS. 
do tempo. Destaca-se a existência de um processo de municipalizaçáo do ensino, com a rede municipal crescendo em todos os estados com exceção do Paraná, onde aumentou o número de municípios em que a rede estadual é predominante. A municipalização ocorre em ritmos diferentes dentro de cada estado. Exemplo disso são Espírito Santo e Goiás, onde o processo de municipalização foi mais intenso que a média do País, e Minas Gerais e Tocantins, onde o processo foi menos intenso.

Dois outros pontos que chamam atenção são o predomínio da rede municipal na região Nordeste, já em 2000, e o baixo predomínio da rede privada de ensino no País. Apesar de o número de matrículas na rede privada ter crescido nos últimos anos, as redes privadas de ensino são predominantes em apenas 14 municípios distribuídos pelo País. Portanto, apesar de as redes privadas de ensino apresentarem crescimento, elas não chegam a competir com as redes públicas.

A trajetória das matrículas no ensino fundamental traz um quadro geral de como prefeitos e governadores de diferentes municípios e estados têm se articulado em torno da municipalização do ensino, assim, criando uma tendência de predomínio das redes municipais, com declínio das redes estaduais de ensino. O FUNDEF não deve ser identificado como o principal responsável pela municipalização do ensino fundamental, pois os mesmos estímulos que foram dados aos municípios para que eles expandissem suas redes de ensino fundamental também foram dados aos estados para que eles fizessem o mesmo. Portanto, as negociaçóes entre prefeitos e governadores seriam tão essenciais para a municipalização do ensino fundamental quanto o próprio FUNDEF (GOMES, 2009). Os diferentes cenários em cada um dos estados são consequências das diversas estratégias escolhidas por esses agentes para lidar com a questão do acesso ao ensino fundamental.

\section{Gastos em educação}

Neste tópico são analisados os gastos em educação dos governos municipais de acordo com os dados disponíveis no site do Sistema de Informaçōes sobre Orçamentos Públicos em Educação (SIOPE), do Fundo Nacional de Desenvolvimento da Educaçáo (FNDE) e do banco de dados Finanças do Brasil (FINBRA). Pode-se argumentar que esses indicadores não representam fielmente as preferências dos prefeitos, uma vez que gastos não se traduzem diretamente em políticas específicas (ESPING-ANDERSEN, 1991). Entretanto, eles são peças importantes para se compreender como tem ocorrido o desenvolvimento da política de educação nos municípios brasileiros.

Durante o período de 2008 a 2014, houve pouca variação na média do total das receitas municipais destinadas à educação. Essa pequena variação, em grande parte, deve-se ao mínimo de $25 \%$ das receitas tributárias municipais que a Constituição exige que os municípios gastem com educaçãó ${ }^{4}$. Devido ao fato de que tal inércia é explicada por determinaçōes da Constituiçâo de 1988, não há porque acreditar que 
no período entre 1988 e 2007 o comportamento dos gastos dos prefeitos tenha sido muito diferente daquele apresentado no Gráfico 18. Ainda assim, a partir de 2010, mesmo dentro deste cenário aparentemente estático, houve mudança significativa na orientação dos municípios em relação aos seus gastos com educação infantil e ensino fundamental (Gráficos 19 a 21).

Apesar de o ensino fundamental ainda ser de longe a área predominante na alocação de gastos em educação da esfera municipal, pouco tempo após a implementação do FUNDEB, os gastos no ensino fundamental sofreram importantes reduçôes. $\mathrm{O}$ gasto em educação infantil cresceu quase que na mesma proporção em que o ensino fundamental foi reduzido. Mesmo com o acesso ao ensino fundamental já universalizado, em 2000, a média dos gastos em ensino fundamental e educação infantil sugere que pouco esforço era realizado pelos municípios para expandirem o acesso aos demais níveis de ensino antes da implementação do FUNDEB.

O efeito das políticas do governo federal sobre as políticas desenvolvidas pelos demais entes federados pode ser examinado pela determinação federal de valores mínimos a serem gastos por aluno no período de um ano ${ }^{5}$, como mostra o Gráfico $20^{6}$.

\section{Gráfico 18}

Média da receita tributária dos municípios destinada à MDE (2008-2014).

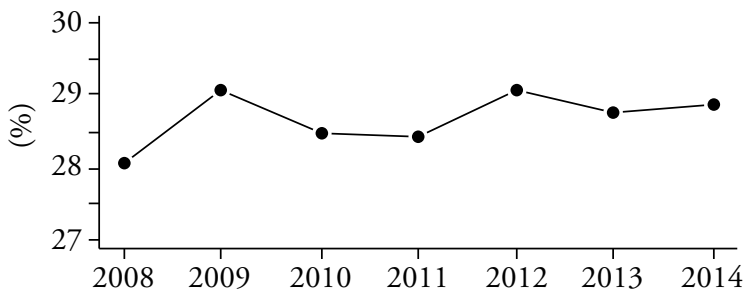

Nota: Dados baixados em 19/08/2015.

Fonte: SIOPE.

\section{Gráfico 19}

Média do gasto em educação (\%) destinado ao ensino fundamental pelos municípios (2005-2012).

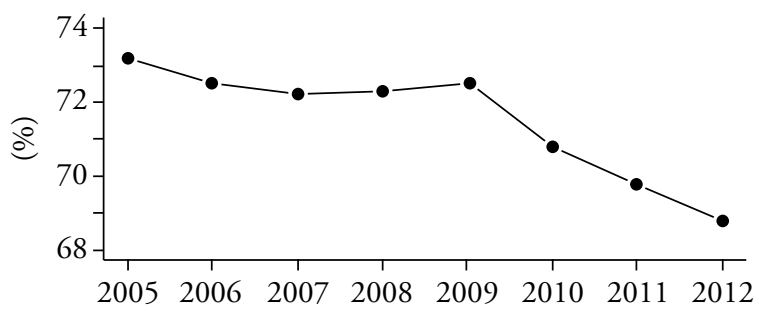

Fonte: FINBRA - Finanças do Brasil (2005-2012). 
As políticas adotadas pelo governo federal impulsionaram a expansão das redes de creches e fizeram com que os governos municipais passassem a dar mais atenção à educação infantil. Como a Figura 1 mostra, o acesso às creches continua pequeno; entretanto, ele tem passado por significativa expansão nos anos posteriores à implementação do FUNDEB e o estabelecimento de valores mínimos a serem gastos com alunos da educação infantil.

A implementação do ensino fundamental com duração de nove anos reduziu o atendimento das pré-escolas às crianças de quatro a cinco anos. Isso combinado às variaçóes demográficas corrobora para que as creches sejam as maiores beneficiárias das expansôes nos gastos ocorridos na educação infantil. Como o acesso às creches ainda é restrito e a população de zero a três anos é maior do que a de quatro a cinco anos, há mais beneficiários na expansão do acesso às creches do que na expansão do acesso às pré-escolas, o que sugere que os municípios passarão a investir cada vez mais recursos em suas creches.

\section{Gráfico 20}

Valor mínimo de gasto por aluno/ano estimado pelo governo federal (1998-2014).

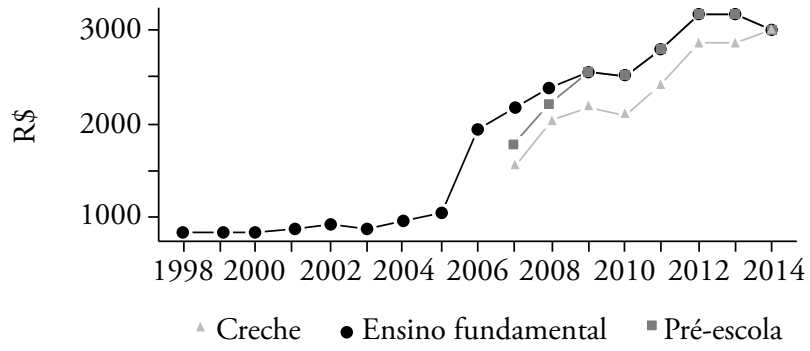

Fonte: www.fnde.gov.br

\section{Gráfico 21}

Média do gasto em educação (\%) destinado à educação infantil pelos municípios (2005-2012).

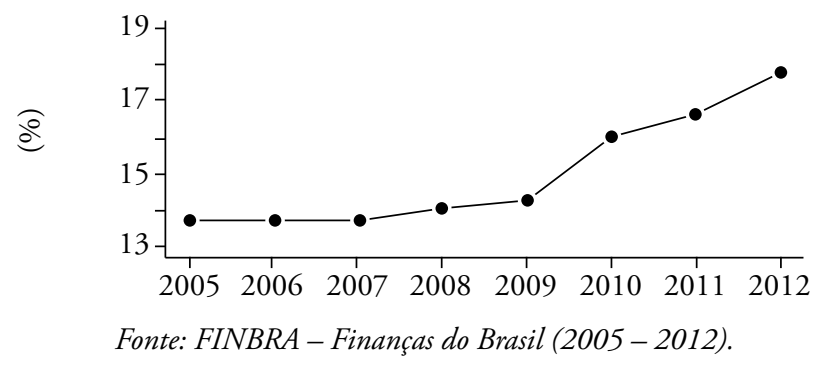


No que diz respeito ao FUNDEF, esses dados também confirmam que, durante o período de sua vigência, o governo federal estabeleceu valores mínimos de gastos por aluno abaixo do legalmente estabelecido pela própria lei do FUNDEF (OLIVEIRA, 2012; RODRIGUEZ, 2001; VAZQUEZ, 2005), pois estes valores tenderam apenas a corrigir a inflação ocorrida no período. Apenas a partir de 2006 houve aumento considerável do valor mínimo estabelecido por aluno do ensino fundamental. O FUNDEB teve grande importância para os demais níveis de ensino, uma vez que valores mínimos a serem gastos por aluno/ano de creches e pré-escolas também passaram a ser determinados pela legislação federal.

As variaçôes ocorridas nos gastos com educação ajudam a captar importantes mudanças nas orientaçóes dos governos locais em relação às suas respectivas políticas de educação e também orientam hipóteses sobre qual será o comportamento futuro dessas redes em relação à expansão do acesso e direcionamento de receitas tributárias. Não há dúvidas de que o ensino fundamental continuará predominante como o nível de ensino que recebe os maiores aportes de recursos dos governos locais. Entretanto, mudanças recentes mostram que os governos locais começam a dar maior atenção a outros níveis de ensino e que nem todos optam automaticamente por expandir a educação infantil, pois o aumento nas receitas destinadas à educação infantil não foi exatamente igual à redução da receita destinada ao ensino fundamental. Isso também implica maior heterogeneidade nas políticas adotadas pelos governos locais no futuro.

Apesar de a Uniáo ter capacidade de influenciar as políticas dos governos subnacionais e promover maior homogeneidade entre elas, percebe-se que o que tem ocorrido mais recentemente, como resultado de sua intervenção, foi precisamente o contrário. As mudanças recentes ampliaram a margem de escolhas dos gestores locais ao estabelecerem novas obrigaçôes e estímulos para que fosse dada atenção a outros níveis de ensino. Desse modo, em comparação com o período de vigência do FUNDEF, os custos para os governos subnacionais diversificarem suas políticas foi consideravelmente reduzido.

\section{Conclusão}

As mudanças ocorridas no acesso ao ensino e nos gastos com educaçáo no Brasil, durante o período de 2000 a 2014, trazem importantes informaçóes sobre as diversas políticas de educação adotadas tanto pela União quanto pelos governos subnacionais e ajudam a traçar um quadro que resume de forma rica as transformaçôes ocorridas no País.

O período de vigência do FUNDEF caracterizou-se por diretrizes do governo federal que foram mais restritivas em relação ao policy decision making dos governos subnacionais. Foram estabelecidos importantes estímulos e restriçóes para que os governos subnacionais focassem seus esforços em ampliar o acesso ao ensino fundamental e adotadas delimitaçóes importantes sobre quais gastos deveriam ser considerados como gastos em manutenção e desenvolvimento do ensino. 
Nesse período, um achado deste artigo que se destaca é o crescimento do acesso às pré-escolas no País, mesmo sem estímulos da União para que isso ocorresse.

O período seguinte, aquele de vigência do FUNDEB, trouxe maior variedade nos estímulos dados aos governos subnacionais para expandirem o acesso ao ensino e também restriçóes novas no que se refere a valores mínimos de gastos na educação infantil. Esse novo cenário impulsionou o crescimento das creches e estimulou maior distribuição dos gastos dos governos subnacionais entre os diferentes níveis de ensino. Nesse período, contrariamente ao esperado, as matrículas em pré-escolas diminuíram, mas o atendimento ao público em idade ideal para cursar esse nível de ensino aumentou devido à implementação do ensino fundamental com duração de nove anos.

A municipalização do ensino fundamental ocorre de forma desigual no País. A região nordeste já havia realizado o processo no início dos anos 2000, enquanto, no período de 2000 a 2012, o processo andou em direção contrária no estado do Paraná, havendo crescimento do número de municípios em que a participação da rede estadual de ensino é predominante. Isso mostrou como a participação dos governos estaduais é essencial nas mudanças que são observadas no nível local, pois mesmo havendo um movimento de municipalização do ensino fundamental no País, como consequência da influência dos governos estaduais nessa questão, esse mesmo movimento processou-se de forma diferente nos estados.

A maior variação nos gastos dos governos municipais entre os diferentes níveis de ensino ocorrida nos últimos anos indica a tendência de maior diversificação entre as escolhas dos governos municipais para suas políticas de educação. $\mathrm{O}$ ensino fundamental continuará sendo o nível de ensino em que os municípios tendem a concentrar o maior número de matrículas e gastos. Entretanto, como a elevação dos gastos em educação infantil não cresceu na mesma proporção em que os gastos destinados ao ensino fundamental foram reduzidos, é possível observar que alguns governos locais já aumentaram seus gastos em outros níveis de ensino além daqueles aqui destacados.

As agendas do governo federal e dos governos estaduais influenciam e atuam sobre a agenda do governo local, entretanto elas não são suficientes para acabar com a autonomia decisória do governo municipal. $\mathrm{O}$ governo local tem poder para adotar agendas próprias de educação, apesar das restriçóes impostas ao seu policy decision making. O retrato do acesso ao ensino e da distribuição dos gastos em educação no País nos anos recentes mostra como as escolhas dos diferentes governos combinaram-se e formaram padróes de maior uniformidade ou de maior divergência em diversas questóes relacionadas à política de educação.

\section{Notas}

1. A Emenda Constitucional 24/1983, mais conhecida como emenda Calmon, havia estabelecido que a União aplicaria em ensino, no mínimo, $13 \%$ de suas receitas de imposto e que os estados, municípios e o Distrito Federal aplicariam, no mínimo, 25\% de suas receitas também em ensino. 
Essa obrigatoriedade vigorava no contexto de elaboração da Constituiçấo de 1988 e certamente influenciou a decisão dos patamares mínimos de gasto então estabelecidos pela nova Constituição.

2. Para simplificar a análise, foi assumido que a demanda por matrículas limita-se à população em idade ideal para cursar cada nível de ensino analisado. Assim, para o período anterior à implementaçáo do ensino fundamental com duraçáo de nove anos, a populaçáo em idade ideal e a demanda por matrículas em creches é a de zero a três anos; a populaçâo em idade ideal e a demanda por matrículas em pré-escolas é a de quatro a seis anos; e a populaçáo em idade ideal e a demanda por matrículas no ensino fundamental é a de sete a catorze anos. Para o período posterior à implementaçáo do ensino fundamental com duraçáo de nove anos, as pessoas em idade ideal e a demanda por matrículas em creches, pré-escolas e no ensino fundamental são as de zero a três anos, quatro a cinco anos e seis a catorze anos, respectivamente. Essa simplificação é mais comprometida quando o ensino fundamental é objeto de análise, pois é ali que há maior distorção idade-série. Entretanto, não são exploradas questóes relacionadas ao desvio idade-série, pois um dos objetivos deste artigo é fazer um diagnóstico do acesso à educaçáo mediante o provimento de matrículas pelos diferentes níveis de governo, e não fazer um acompanhamento do desempenho escolar dos alunos.

3. A Lei 11.274/2006 estabeleceu a implementação gradual do ensino fundamental com duraçáo de nove anos a partir da incorporação de crianças de seis anos ao ensino fundamental. A lei previa que até 2010 todos os entes federados deveriam estabelecer a obrigatoriedade do ensino fundamental com duração de nove anos. Entretanto, em 2012, ainda é possível observar no Censo Escolar municípios que matriculam crianças de seis anos no ensino pré-escolar, apesar de em número cada vez menor.

4. A esta restrição acrescenta-se que a Lei Orgânica de muitos municípios estabelece valores mínimos mais elevados do que estes.

5. A determinação desses valores deu-se mediante decretos presidenciais e portarias interministeriais.

6. A partir de 1999, o governo federal passou a distinguir o ensino fundamental em anos iniciais e anos finais. O valor exibido é uma média dos dois valores. A partir de 2005, além da divisão já existente no ensino fundamental, o governo federal passou a determinar valores diferentes para o ensino fundamental rural e para o urbano. Novamente, os valores exibidos são a média resultante dos valores dos anos iniciais e finais do ensino fundamental e do ensino fundamental urbano e rural. A partir de 2006, o governo federal passou a declarar valores mínimos no gasto por aluno específicos para cada estado do País. O valor exibido no gráfico, a partir de então, também é a média dos valores mínimos que cada estado deveria gastar. O exercício de tirar a média do gasto mínimo por município retorna valores muito semelhantes aos exibidos. Os valores do gráfico foram corrigidos pela inflação tendo o ano de 2014 como ano-base. Os valores mínimos de gasto por aluno/ano são definidos em decretos e em portarias devido às diretrizes estabelecidas nas Leis 9.424/1996 e 11.494/2007, leis que regulamentam o FUNDEF e o FUNDEB, respectivamente.

\section{Referências}

AGUIAR, M.A.S. Avaliação do Plano Nacional de Educação 2001-2009: questóes para reflexão. Educação \& Sociedade, v. 31, n. 112, p. 707-727, 2010. 
ARRETCHE, M. Continuidades e descontinuidades da federação brasileira: de como 1988 facilitou 1995. Dados, v. 52, n. 2, p. 377-423, 2009.

BERQUÓ, E.; CAVENAGHI, S. Fecundidade em declínio: breve nota sobre a redução no número médio de filhos por mulher no Brasil. Novos Estudos CEBRAP, Sáo Paulo, n. 74, p. 11-15, mar. 2006.

CAMPOS, B.C.; CRUZ, B.P.A. Impactos do FUNDEB sobre a qualidade do ensino básico público: uma análise para os municípios do Estado do Rio de Janeiro. Revista de Administração Pública, v. 43, n. 2, p. 371-393, 2009.

COSTA, B.L.D.; DUARTE, V.C. Os efeitos do FUNDEF nas políticas educacionais dos municípios mineiros. Educação em Revista, n. 48, p. 143-170, 2008.

DUARTE, M.R.T. Regulação sistêmica e política de financiamento da educação básica. Educaçâo \& Sociedade, v. 26, n. 92, p. 821-839, 2005.

ESPING-ANDERSEN, G. As três economias políticas do Welfare State. Lua Nova, n. 24, p. $85-116,1991$.

GOMES, S. Políticas nacionais e implementação subnacional: uma revisão da descentralização pós-FUNDEF. Dados, v. 52, n. 3, p. 659-690, 2009.

OLIVEIRA, R.L.P. Direito à educação e federalismo no Brasil. Retratos da Escola, v. 6, n. 10, p. 39-47, 2012.

PINTO, J.M.R. Financiamento da educação no Brasil: um balanço do governo FHC (1995-2002). Educação \& Sociedade, v. 23, n. 80, p. 108-135, 2002.

RIGOTTI, J.I.R. Transição demográfica. Educação e Realidade, Porto Alegre, v. 37, n. 2, p. 467-490, ago. 2012.

RODRIGUEZ, V. Financiamento da educação e políticas públicas: o FUNDEF e a política de descentralização. Cadernos CEDES, n. 55, p. 42-57, 2001.

SÁTYRO, N.G.D. Politica e instituiçóes e a dinâmica das politicas sociais nos estados brasileiros: uma análise após a redemocratização. (Tese de Doutorado) - Rio de Janeiro, Universidade Cândido Mendes, 2008.

SEMEGHINI, U.C. Fundef: uma revolução silenciosa. Brasília: MEC, 2001.

SOUZA, D.B.; FARIA, L.C.M. Reforma do estado, descentralização e municipalização do ensino no Brasil: a gestão política dos sistemas públicos de ensino pós-LDB 9.394/96. Ensaio: Avaliação e Políticas Públicas em Educação, v. 12, n. 45, p. 925-944, 2004.

VAZQUEZ, D. A. Desequilíbrios regionais no financiamento da educação: a política nacional de equidade do FUNDEF. Rev. Sociol. Polit., Curitiba, n. 24, p. 149-164, jun. 2005.

Recebido em 14 de julho de 2016.

Aprovado em 06 de janeiro de 2017. 